\title{
Predicting moral attitudes and antisocial behavior in young team sport athletes: A self-determination theory perspective
}

\author{
Luca Mallia $^{1}$ (D) | Fabio Lucidi ${ }^{2}$ | Arnaldo Zelli ${ }^{1}$ | Andrea Chirico ${ }^{2}$ | Martin S. Hagger,4,5
}

\author{
${ }^{1}$ Department of Movement, Human and \\ Health Sciences, University of Rome "Foro \\ Italico", Rome, Italy \\ ${ }^{2}$ Department of Social and Developmental \\ Psychology, "La Sapienza" University of \\ Rome, Rome, Italy \\ ${ }^{3}$ School of Psychology and Speech \\ Pathology, Curtin University, Perth, Australia \\ ${ }^{4}$ Faculty of Sport and Health \\ Sciences, University of Jyväskylä, Jyväskylä, \\ Finland \\ ${ }^{5}$ Department of Physical Education, Hong \\ Kong Baptist University, Hong Kong, \\ Hong Kong

\section{Correspondence} \\ Luca Mallia, Department of Movement, \\ Human and Health Sciences, University of \\ Rome "Foro Italico", Largo Lauro de Bosis 5, \\ Rome 00135, Italy. \\ Email: luca.mallia@uniroma4.it
}

\begin{abstract}
Identifying the factors associated with prosocial and antisocial behaviors in youth sport may provide evidence to inform interventions aimed at promoting prosocial behaviors and minimizing rule transgressions in young athletes. We investigated relations among social-contextual factors (e.g., social support), personal motivational factors (e.g., psychological need satisfaction and motivation), young athletes' attitudes toward prosocial (e.g., keeping winning in proportion) and antisocial (e.g., acceptance of cheating and gamesmanship) behaviors, and their actual rule violations during matches in two samples of athletes. Participants in Sample 1 were young team sport athletes $(N=355)$ and participants in Sample 2 were young male futsal players $(N=296)$. Athletes in Sample 1 completed validated self-report measures of perceived autonomy support, basic need satisfaction, and autonomous and controlled motivation from self-determination theory, moral attitudes, and past cheating behaviors. Athletes in Sample 2 completed identical measures and two additional behavioral measures: athletes' self-reported number of yellow cards received during competition in the last 6 months and the number of yellow cards athletes received from referees in the subsequent 2 months from competition records. We found significant relations between psychological need satisfaction and self-determined motivation, and athletes' moral attitudes in both samples. These effects held when statistically controlling for past behavior. Importantly, our prospective analysis of Sample 2 indicated that attitudes toward antisocial behaviors predicted athletes' rule violations during subsequent tournament matches. Findings indicate that promoting autonomous motivation and need satisfaction through autonomy support may foster attitudes toward prosocial behaviors, and minimize rule transgressions, in young athletes.
\end{abstract}

\section{1 | INTRODUCTION}

Research on prosocial and antisocial behavior in sport has indicated that a substantive minority of athletes engage in behaviors considered ethically inappropriate in sport, such as injuring an opponent, cheating, retaliating to a foul, faking an injury, or engaging in behaviors that will psychologically distract or upset the opponents (Boardley \& Kavussanu, 2007; Lee, Whitehead, \& Ntoumanis,
2007; Lee, Whitehead, Ntoumanis, \& Hatzigeorgiadis, 2008; Long, Pantaléon, Bruant, \& D'Arripe-Longueville, 2006). Although many of these behaviors contravene the rules and regulations of sport and are duly sanctioned if identified by officials or in retrospective evidence (e.g., TV, video footage), some behaviors go undetected and others are not considered rule transgressions but are still considered contrary to the "spirit" of fair play and moral conduct in sport. This presents considerable problems when the goal of sport, even at the 
highest level, is to ensure fair competition in which success and winning are attributable to superior ability, tactics, effort, and preparation and done so on a "level playing field."

\section{1 | Attitudinal antecedents of prosocial and antisocial behaviors in sport}

Much research on prosocial and antisocial behaviors in sport has been concerned with describing how athletes conduct themselves when performing their sport (e.g., whether they respect rules and officials or comply with conventions). Vallerand, Briere, Blanchard, and Provencher (1997) developed a social psychological model to move beyond mere description and provided a deeper understanding of the antecedent factors of these behaviors and sportspersonship in sport, arguing that prosocial and antisocial behavior should be understood both in terms of individual characteristics, including attitudes toward antisocial behaviors (i.e., acceptance of cheating and acceptance of gamesmanship) and prosocial behaviors (i.e., keeping winning in proportion) (e.g., Lee et al., 2007), and contextual characteristics (Vallerand et al., 1997).

Research has also stressed the need to treat cheating and gamesmanship in sport as separate behaviors (Cruz et al., 2018; Lee et al., 2007; Palou et al., 2013; Ponseti et al., 2012). Both behaviors are considered goal-directed with the purpose of yielding an illegitimate advantage. However, while cheating is characterized by explicit ruleviolation acts (e.g., doping, professional fouls), gamesmanship represents subtler, dishonorable behaviors that are at odds with sport ethics with the aim of gaining an advantage over the opponent, but without a de jure violation of the rules. Examples include "sledging"the deliberate verbal haranguing and mocking of an opponent, so as to upset their concentration or provoke retaliation (Lee et al., 2007; Lucidi et al., 2017; Ponseti et al., 2012). However, with few exceptions (e.g., Lucidi et al., 2017), existing literature on this topic (e.g., d'Arripe-Longueville, Corrion, Scoffier, Rousse, \& Chalabaev, 2010; Gonçalves, e Silva, Cruz, Torregrosa, \& Cumming, 2010; Lee et al., 2008; Ntoumanis \& Standage, 2009) does not explicitly address the relationship between attitudes toward these antisocial behaviors and athletes' actual behaviors during sport competitions.

\section{2 | Toward a motivational model of antisocial behaviors in sport}

The identification of the antecedent factors of athletes' moral attitudes and antisocial behaviors is essential to understand the processes that lead to cheating and gamesmanship in sport. Several authors (e.g., Boardley, Kavussanu, \& Ring, 2008; Kavussanu, Seal, \& Phillips, 2006; Mallia et al., 2018; Ntoumanis \& Standage, 2009) have claimed that the reasons why athletes participate in sport (i.e., their motives) influence their behavior, including their prosocial and antisocial behaviors. Specifically, researchers have turned to theories of motivation, such as achievement goal theory (Duda, 1992) or sport commitment model (Scanlan, Carpenter, Schmidt, Simons, \& Keeler, 1993) to provide a framework for understanding how motivation is related to antisocial behaviors like cheating and gamesmanship in sport. Prominent among these motivational theories is self-determination theory (Deci \& Ryan, 1985; Ryan \& Deci, 2017). The theory has utility in identifying both the personal and the contextual/environmental factors that influence individuals' motivation and, importantly, the origins of these motives. Central to the theory is the distinction between autonomous and controlled forms of motivation. Autonomous motivation relates to engaging in behaviors for personally endorsed reasons and to knowledge that the behavior is consistent with personal values. Controlled motivation, on the other hand, reflects engaging in behavior for reasons perceived as external to the individual and, is therefore, other rather than self-endorsed. Both forms of motivation make behavioral engagement more likely, but autonomous motivation tends to be related to more adaptive outcomes and behavioral persistence because it is related to selfendorsed reasons for acting, while controlled motivation is less adaptive because it is viewed as externally referenced and, therefore, only likely to persist, as long as the external contingencies are present.

\section{3 | Antecedents of autonomous and controlled motivation}

According to the self-determination theory, the type of motivation adopted toward behaviors is generally dependent on the extent to which the behavior is perceived to satisfy three innate, basic psychological needs: autonomy, competence, and relatedness. Behaviors that satisfy these needs are more likely to be experienced as autonomous, and individuals are likely to engage in these behaviors out of a sense of personal ownership and volition and more likely to persist with the behaviors. Given that autonomous motivation leads to adaptive behavioral outcomes and persistence, it may be that fostering autonomous motivation and need satisfaction can assist in promoting prosocial behaviors in sport and minimizing antisocial behaviors.

Autonomous motivation can be promoted by fostering need satisfaction through the socio-contextual environments generated by figures of authority and significant others (Reeve, 1998). Such environments (e.g., school, family, and sport team) are known as autonomy supportive environments and support individuals' autonomous choices and individual volition, minimize external pressure and control, acknowledge negative feelings, and offer a rationale for engaging in activities (e.g., Ryan \& Deci, 2000). For example, parents and coaches acting in an autonomy supportive manner are more likely to promote athletes' own choices, to give them opportunities for initiative, and to offer positive, informative, and constructive feedback. They are also capable of offering a rationale to explain the decisional process underlying the need to respect rules and norms that are often inherent to complex social systems (e.g., family and sport team). Autonomy supportive interventions have demonstrated considerable efficacy in promoting autonomous motivation and persistence on tasks and behaviors in multiple contexts (Hagger \& Chatzisarantis, 2015; Ryan \& Deci, 2017). 


\section{4 | A self-determination theory perspective on prosocial and antisocial behaviors in sport}

Previous research has shown that personal (e.g., types of motivation and basic needs satisfaction) and socio-contextual (e.g., autonomy support) factors are related to moral attitudes, as well to social and antisocial behaviors in sport (e.g., Hodge \& Lonsdale, 2011; Ntoumanis \& Standage, 2009; Sheehy \& Hodge, 2015). Research has indicated that autonomy supportive contexts fostered by key figures such as coaches and parents positively promotes athletes' satisfaction of their basic psychological needs (i.e., competence, relatedness, and autonomy). The satisfaction of these needs increases the likelihood that young athletes will experience sport as autonomously motivated. This is adaptive from a moral behavior perspective given research demonstrating that autonomous motivation is positively related to athletes' attitudes toward prosocial behaviors and negatively related to their attitudes toward antisocial behaviors in sport (i.e., cheating and gamesmanship).

The likely process by which autonomous motivation fosters attitudes toward prosocial behaviors is through internalization and integration processes. Athletes experiencing their sport as autonomous are more likely to internalize all aspects of the sport and to view their involvement as an important part of their genuine sense of self. The internalization of rules is part of sport motivation, as athletes value the game as an entity which includes all aspects from tactics to rules and fair play. This "ownership" over sport participation is also likely to extend to an assimilation of the rules, fair play, and responsibility toward others in the sporting context. Autonomously motivated athletes are also more likely to view achievement in sport as intrinsic or self-referenced, rather than extrinsic or other-referenced. Therefore, seeking to gain external recognition or other extrinsic rewards, like money, through winning is likely to be secondary to self-referenced markers of success, like mastering the task and fulfilling their team role effectively.

More complex pattern of predictions relates to the role of controlled motivation and its relation to prosocial and antisocial behaviors in sport. The need for competence is positively related to controlled motivation (e.g., Ntoumanis \& Standage, 2009) which, on the surface, appears to contrast with theory predictions. However, researchers have indicated that individuals can satisfy their need for competence without feeling autonomous. For example, an athlete can feel competent in completing a sport task or skill, but may still feel that his/her participation in the task is controlled by external forces (e.g., they feel obliged to do the task for others or do the task to gain recognition, acceptance, or a reward) or may be guided by internal motives (e.g., engage in the task in order to maintain contingent self-worth or to avoid negative emotional states such as shame, guilt or anxiety, if they do not). Controlled motivation, however, is proposed to have a negative impact on attitudes toward prosocial behaviors and a positive impact on attitudes toward antisocial behaviors in sport. Athletes who feel that they are controlled by internal pressures, such as feelings of guilt or shame, and fear of punishment (by parents, coaches, or teammates), or by external pressures, such as the desire to attain extrinsic rewards, are unlikely to have internalized the sport as an important part of their genuine self, and instead more likely to view the attainment of external/ internal contingencies as the only goal or purpose of participation. They might, therefore, be more likely to engage in any kind of behavior, even antisocial behaviors, in order to succeed, particularly if they view sanctions or punishments for antisocial behaviors as unlikely. This is epitomized by the "win at all costs" or the "the ends justify the means" reasons that athletes tend to use to justify these behaviors.

Finally, a hypothesis arising from the model that has yet to be tested in research on moral attitudes in sport is the effect of autonomous motivation and prosocial attitudes on future antisocial or transgressive behaviors. It is hypothesized that individuals reporting autonomous motivation and positive attitudes toward prosocial behaviors are less likely to engage in future transgressive and antisocial behaviors (e.g., fouls or breaking rules), whereas individuals endorsing controlled motivation and positive attitudes toward antisocial behaviors are more likely to engage in these types of transgressions.

\subsection{The importance of past behavior}

An important consideration when evaluating the effectiveness of social cognitive and motivational theories in explaining behavioral outcomes is the extent to which the predictions hold when controlling for past behavior. There is a considerable body of research that has demonstrated attenuation or even extinction of effects in tests of social psychological models once a measure of past behavior has been included alongside the theory predictors (Ajzen, 2002; Conner, Warren, Close, \& Sparks, 1999; Hagger, Chan, Protogerou, \& Chatzisarantis, 2016; Hagger, Polet, \& Lintunen, 2018; Ouellette \& Wood, 1998; Sutton, 1994). Past behavior, often conceptualized as the frequency with which an individual has engaged in the behavior of interest in the past, tends to model the effects of unmeasured variables in the model that explain the consistency or stability of the behavior over time (Hagger et al., 2018; Ouellette \& Wood, 1998). Some researchers have suggested that such effects reflect habitual or nonconscious influences on behavior (Ouellette \& Wood, 1998). Importantly, theorists have indicated that inclusion of past behavior in social cognitive and motivational theories provides an important test of the sufficiency of the theories in explaining behavior. If the effects of social cognitive and motivational variables on behavior were extinguished or rendered trivial by the inclusion of past behavior, then the model would be rendered insufficient as an explanation of behavior (Hagger et al., 2016; Hagger \& Chatzisarantis, 2016). Such findings also mean that any intervention or manipulation to change the theory variables will have no effect on behavior. The inclusion and control for past behavior in tests of theories and models is therefore advocated as it provides a robust test of its sufficiency. In the context of the current research, previous studies testing the hypotheses of models to explain moral behavior in sport have not generally considered or accounted for previous behavior. Without these data, researchers cannot definitively conclude that 
the effects of psychological antecedents like prosocial and antisocial attitudes and motivational constructs from self-determination theory reflect the true effects among the constructs in the absence of past behavior. Consequently, research that tests these effects when controlling for the effects of past behavior would make a valuable contribution to knowledge and assist in determining the sufficiency of the model in accounting for unique variance in moral behavior in sport.

\subsection{The present research}

The present research aimed to test the general hypothesis that social-contextual (i.e., social support) and personal motivational (i.e., need satisfaction and motivation) factors from SDT are related attitudes toward prosocial (e.g., keeping winning in proportion) and antisocial (e.g., acceptance of cheating and gamesmanship) behaviors in youth sport, as well as to negative sport behaviors.

With this broad hypothesis in mind, we firstly sought empirical confirmation of Ntoumanis and Standage's (2009) model of moral functioning in sport based on SDT in a large sample of team sport athletes. Figure 1 depicts this model, which specifically hypothesizes that (a) perceived autonomy support from coaches and parents would positively predict young athletes' satisfaction of basic psychological needs (i.e., autonomy, competence, and relatedness); (b) all psychological needs would positively predict athletes' autonomous motivation, and the need for competence would also positively predict controlled motivation; (c) autonomous motivation would negatively predict attitudes toward antisocial behaviors, and positively predict attitudes toward prosocial behaviors; and (d) controlled motivation would positively predict attitudes toward antisocial behaviors and negatively predict attitudes toward prosocial behaviors.

The present research also examined the empirical value of a second model, depicted in Figure 2, which provides a second test of relations proposed in model 1 , and also tests the extent to which these constructs predicted athletes' antisocial behavior in sport competitions. Specifically, this second model hypothesized that attitudes toward prosocial and antisocial behaviors would have positive and negative effects, respectively, on rule-based infringements, as determined by number of infringements (yellow cards) received in competition.

Our analysis extends existing knowledge in several ways. First, we expect to provide a replication of Ntoumanis and Standage's (2009) model in a different national group and in different sports, thus providing a rigorous test of the generalizability of the model. Second, our analysis examines the predictive validity of this model by adopting an externally validated, objective measure of transgressive behavior, namely, the number of yellow cards that athletes received during competitions. In this context, yellow card infringements by athletes were treated as indirect indicators of athletes' antisocial behaviors on the sport field. Finally, our analyses offer the

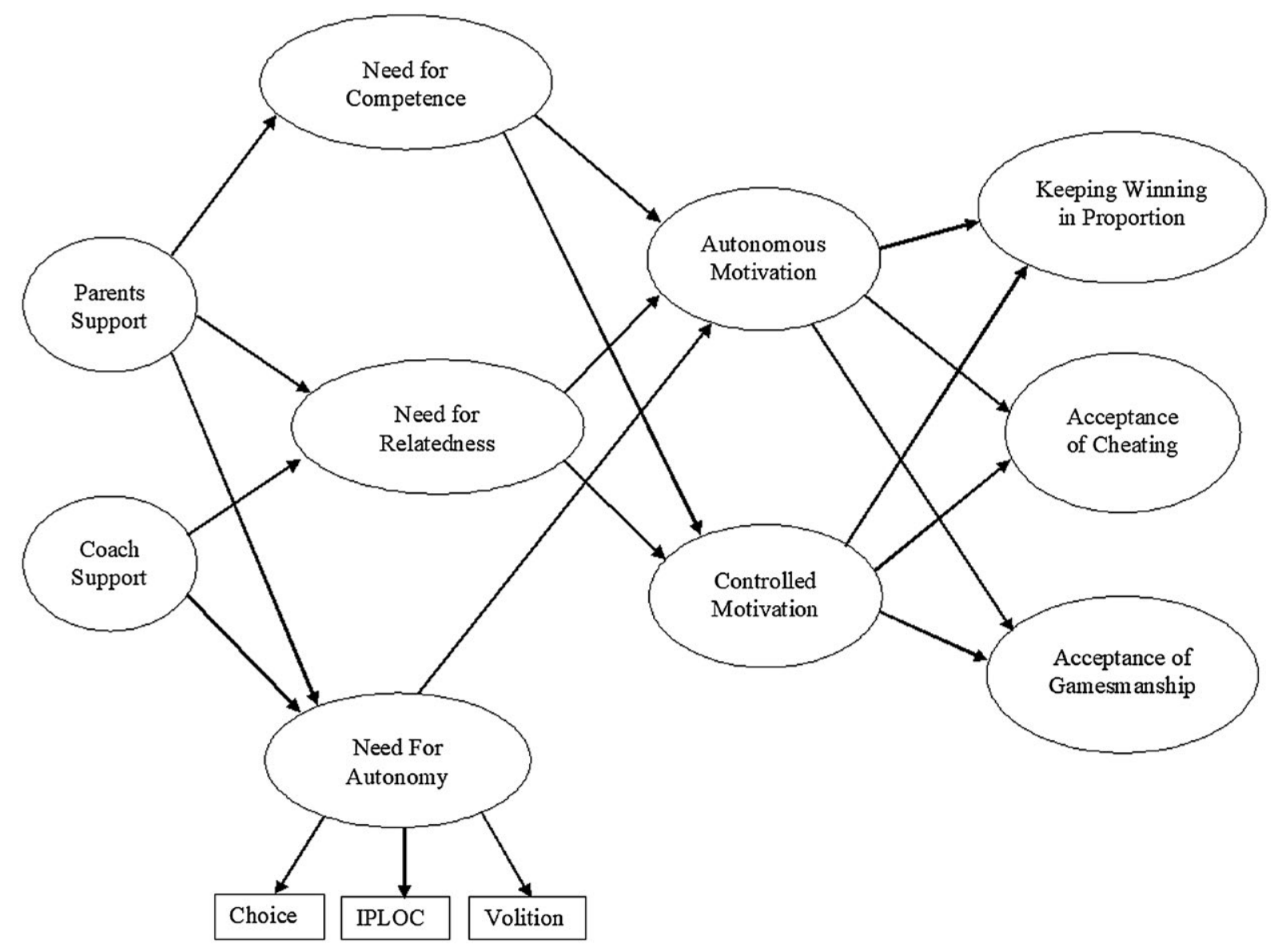

FIGURE 1 Model tested in the first sample of team sport athletes 


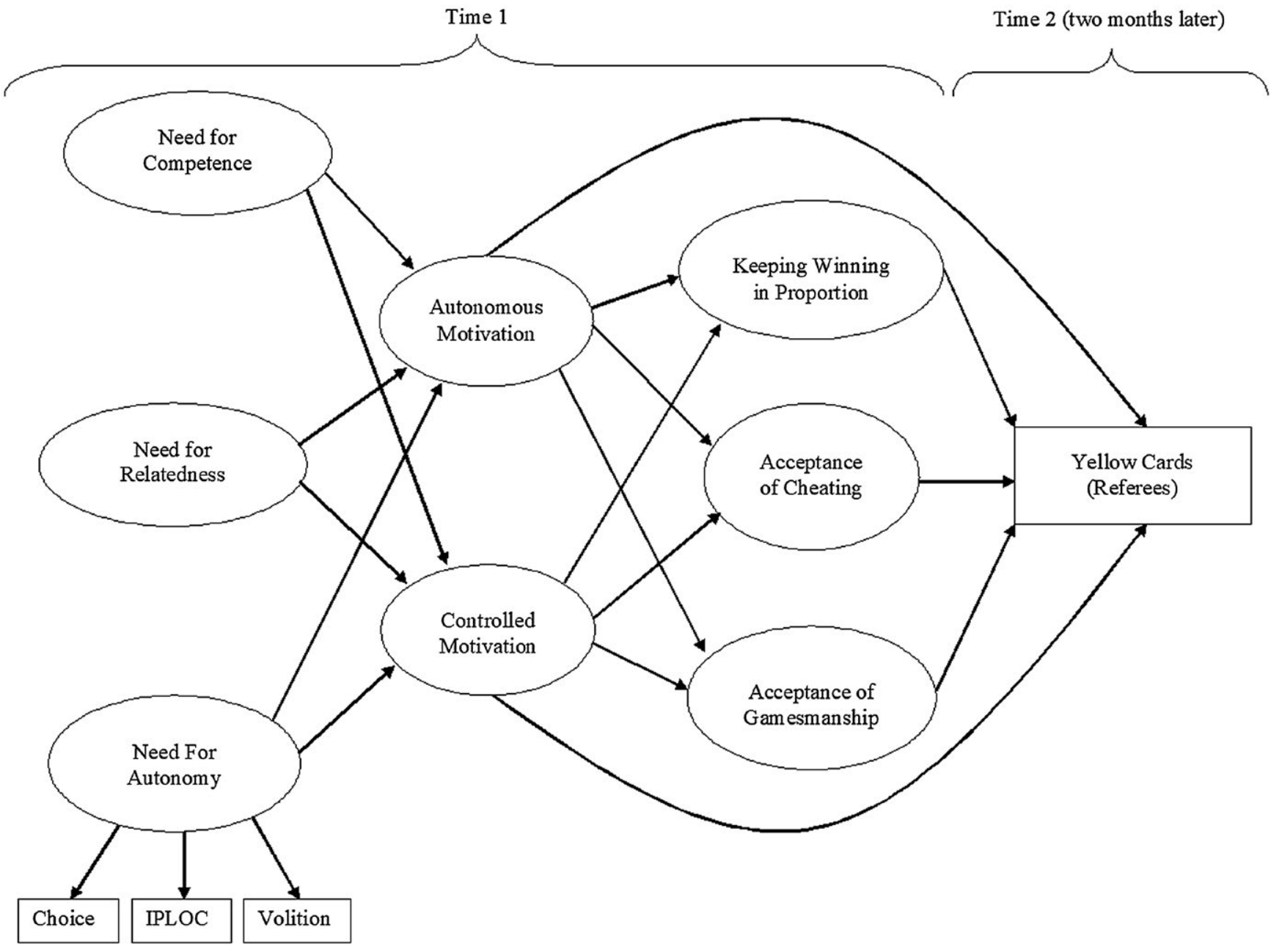

FIGURE 2 Model tested in the second sample of team sport athletes

opportunity to test the proposed effects while controlling for past behavior, an important endeavor when evaluating the effectiveness of psychological models of behavior.

\section{2 | METHOD}

\section{1 | Participants}

Participants were young team sport athletes. We collected data from two separate samples. The first sample (Sample 1) comprised young Italian team sport athletes $(N=355 ; 81.4 \%$ male; $M$ age $=$ 18.98 years, $S D=4.35$ ) participating in soccer ( $n=172 ; 48.5 \%)$, volleyball ( $n=99 ; 27.9 \%$ ), rugby $(n=72 ; 20.3 \%)$, or basketball $(n=12$; 3.4\%). The second sample (Sample 2) comprised young Italian male futsal players $(N=296 ; M$ age $=21.09$ years, $S D=7.56)$. All participants were recruited through direct contact with sport clubs, which voluntarily gave permission to contact their athletes. All recruited athletes gave their consent to participate in the study. The institutional review board of the Department of Social and Developmental Psychology, "La Sapienza" University of Rome approved the study protocol. Participants were informed of the aims and purposes of the study, as well as of their participation rights (e.g., confidentiality of responses, right to withdraw any time without any consequences).

\section{2 | Measures}

Athletes completed a survey containing study measures individually in isolated conditions. Full details of study measures, including reliability coefficients and item characteristics are presented in Appendix A. Athletes in Sample 1 completed validated measures of perceived autonomy support (Grolnick, Ryan, \& Deci, 1991), basic need satisfaction ( $\mathrm{Ng}$, Lonsdale, \& Hodge, 2011), autonomous and controlled motivation (Pelletier et al., 1995), as well as attitudes toward prosocial (i.e., keeping winning in proportion) and antisocial (i.e., acceptance of cheating and acceptance of gamesmanship) behaviors (Lee et al., 2007). Participants also self-reported their past cheating behaviors during their sport activities over the previous 6 months using four items that referred to different sport-related situations (e.g., cheating during a competition). With the exception of the measurement of perceived autonomy support, athletes in Sample 2 completed the same set of psychological and behavioral measures as participants in Sample 1. Athletes in Sample 2 also 
provided an additional behavioral measure by indicating the number of penalties (i.e., yellow cards) they had received during games in the previous 6 months. Finally, this latter behavioral measure was complemented by recording the actual number of yellow cards athletes received from referees during their competitive matches in the subsequent 2 months. The measure was taken from referees' official match reports.

\section{3 | Model tests and statistical analyses}

Fit of the proposed models depicted in Figures 1 and 2 with the data were tested using variance-based structural equation modeling (VB-SEM-also known as Partial Least Squares analysis) with the WARP PLS v.5.0 statistical software (Kock, 2015). Constructs in each model were represented by latent factors indicated by its constituent scale items, with estimated structural relations specified among constructs consistent with the proposed models. Analyses also included a statistical control of the possible effects past self-reported behaviors might have on the key variables of the models. Finally, we tested the invariance of the measurement parameters and structural relations common to both models using multigroup analysis (Kock, 2014). These include relations among the need satisfaction, motivational variables, and attitudes toward prosocial and antisocial behaviors. This analysis allowed us to examine the extent to which the hypothesized relations held across samples of athletes.

In all analyses, construct validity of the latent factors was tested using average variance extracted (AVE) and composite reliability coefficients $(\rho)$ for each factor, which should exceed 0.50 and 0.70 , respectively. Discriminant validity of each factor is supported when the square-root of the AVE for each latent variable exceeds its correlation coefficient with other latent variables (Esposito Vinzi, Chin, Henseler, \& Wang, 2010). In addition, potential multicollinearity was checked using the full collinearity variance inflation factor (AFVIF), with values lower than 3.30 indicative of no issues with multicollinearity (Kock, 2015). Adequacy of the hypothesized model was established using an overall goodness-of-fit (GoF) index given by the square root of the product of the AVE and average $R^{2}$ for the model, with values of $0.100,0.250$, and 0.360 corresponding to small, medium, and large effect sizes, respectively (Tenenhaus, Esposito Vinzi, Chatelin, \& Lauro, 2005). Further information on the adequacy of the model is provided by the average path coefficient (APC) and average $R^{2}$ (ARS) coefficient across the model parameters, both of which should be statistically significantly different from zero. With respect to model effects, each structural relation among model constructs was estimated with standardized coefficients, confidence intervals, and test of difference from zero.

\section{3 | RESULTS}

Table 1 shows the measurement-level statistics of the estimated models. Composite reliability coefficients for each latent factor exceeded the 0.70 criterion. In addition, the square root of the estimated variance extracted by each factor exceeded its correlation with all other latent variables supporting the discriminant validity of each factor. Overall, the analyses showed good fit with the observed data for models 1 (GoF $=0.250 ;$ APC $=0.165, p<0.001$; ARS $=0.093, p=0.019 ; \mathrm{AFVIF}=1.512)$ and $2(\mathrm{GoF}=0.234 ; \mathrm{APC}=0.116$, $p=0.011 ;$ ARS $=0.074, p=0.050 ;$ AFVIF $=1.701)$

Focusing on estimates of proposed effects among model constructs in Sample 1 (Figure 1), perceived autonomy support significantly and positively predicted their need satisfaction for competence, relatedness, and autonomy, both when support was from parents $(\beta=0.15, p=0.002 ; \beta=0.15, p=0.003 ; \beta=0.19, p<0.001$, respectively) and from coaches ( $\beta=0.11, p=0.023 ; \beta=0.30, p<0.001$; $\beta=0.30, p<0.001$, respectively). Consistent with hypotheses, we found significant effects of athletes' need satisfaction on autonomous and controlled motivation for the competence $(\beta=0.20$, $p<0.001 ; \beta=0.26, p<0.001$, respectively), relatedness $(\beta=0.34$, $p<0.001 ; \beta=0.11, p=0.016)$, and autonomy $(\beta=0.12, p=0.014 ; \beta$ $=-0.10, p=0.034)$ needs. As above, these effect sizes remained virtually identical after the statistical control of past cheating behavior. Finally, the analysis also showed significant effects of motivational factors on athletes' moral attitudes. Specifically, athletes' autonomous motivation predicted keeping winning in proportion ( $\beta=0.15$, $p=0.003$ ), and controlled motivation positively predicted acceptance of cheating $(\beta=0.18, p<0.001)$ and gamesmanship $(\beta=0.18$, $p<0.001)$. For these latter two effects, inclusion of past cheating behavior reduced the size of the effects and rendered the effect nonsignificant.

Focusing on the analysis for Sample 2 (see Figure 2). These analyses tested identical effects as model 1 and included effects of model constructs on the number of yellow cards athletes received as an objective measure of cheating behavior. As expected, both acceptance of gamesmanship ( $\beta=0.10, p=0.038$ ) and acceptance of cheating ( $\beta=0.13, p=0.011$ ) positively predicted the behavioral outcome. As also expected, these effects were substantially attenuated with the inclusion of past behavior: the effect of acceptance of gamesmanship was extinguished ( $\beta=0.02, p=0.34$ ), while the effect of acceptance of cheating was significantly reduced but remain significant $(\beta=-0.12, p=0.019)$, although the negative effect which is inconsistent with previous effects was probably attributable to a suppressor effect.

Finally, we tested invariance of the common effects across the two models using multi-group analysis. The analysis provided support for the measurement invariance and equivalence in the hypothesized latent relations among variables. ${ }^{1}$

\section{4 | DISCUSSION}

Based on key tenets from theories of moral attitudes in sport and self-determination theory (e.g., Lee et al., 2007; Ntoumanis

${ }^{1}$ The only exception was the path from autonomous motivation to acceptance of gamesmanship, which was significantly different across the two samples $(t=-2.07 ; p=0.02$ ). 


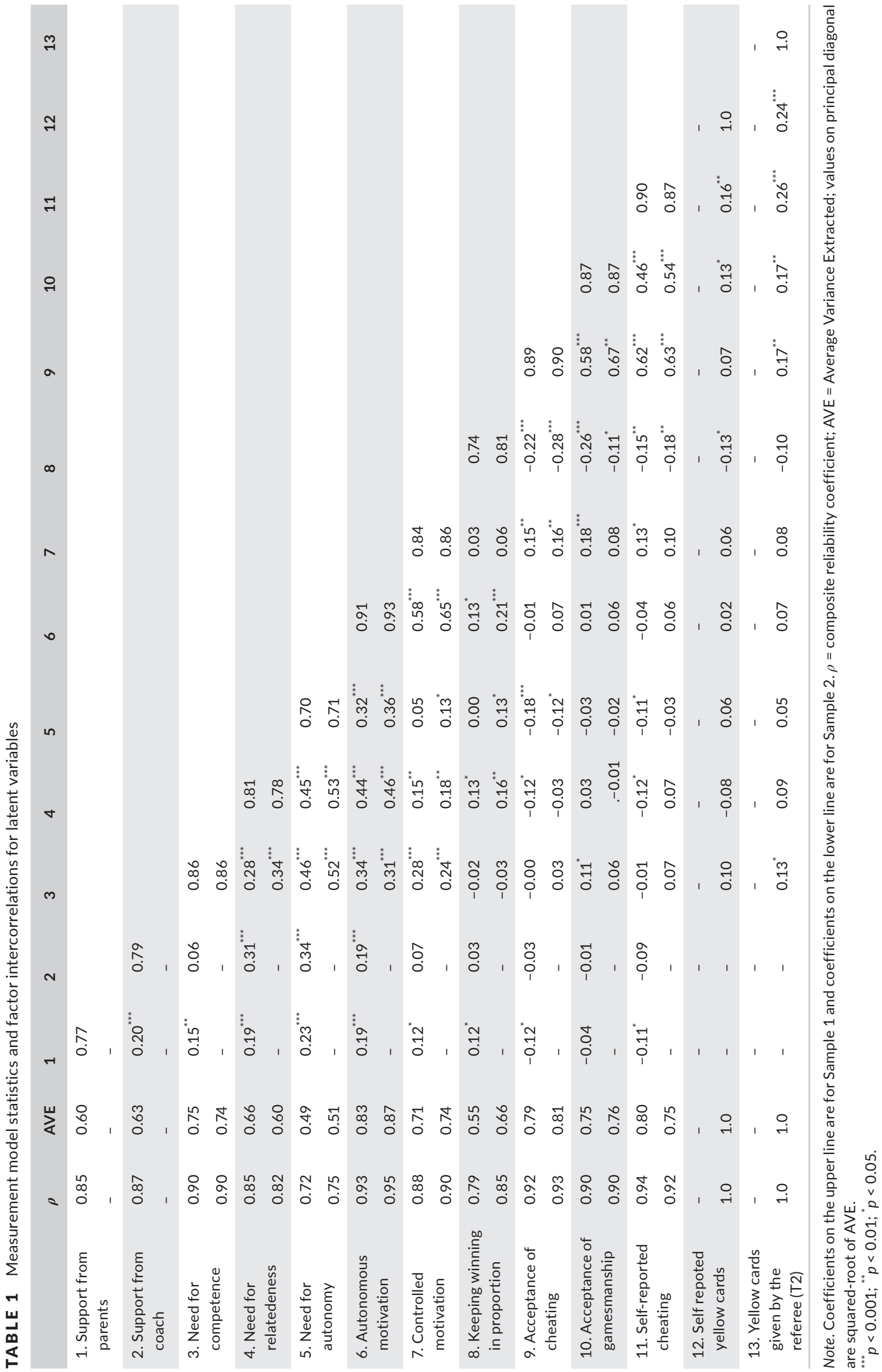


\& Standage, 2009; Vallerand et al., 1997), the present investigation tested an extended version of the Ntoumanis and Standage's (2009) model that comprised three main hypotheses. First, we hypothesized that athletes' perceived autonomy support from parents and coaches would predict athletes' autonomy, competence, and relatedness need satisfaction. Second, we hypothesized that need satisfaction would predict athletes' attitudes toward cheating and gamesmanship through the mediation of autonomous and controlled forms of motivation in sport. Finally, we hypothesized that athletes' attitudes toward cheating and gamesmanship would predict transgressive behaviors in sport.

Our hypotheses were tested in two samples of athletes practicing different sports. Findings provided support for the general hypothesis that motivational factors (i.e., psychological need satisfaction and self-determined forms of motivation) are linked in meaningful ways to athletes' sport-related moral attitudes. Specifically, autonomy, competence, and relatedness need satisfaction predicted athletes' autonomous and controlled motivation and these motivational variables predicted athletes' moral attitudes toward prosocial (keeping winning in proportion) and antisocial (acceptance of cheating and gamesmanship) behaviors. In particular, relations of controlled motivation on attitudes toward cheating and attitudes toward gamesmanship were approximately equal in magnitude, confirming the empirical evidence outlined by several scholars (e.g., Lee et al., 2008; Lucidi et al., 2017; Ntoumanis \& Standage, 2009) that these two attitudes represent empirical indicators of a second orderlatent factor, termed "antisocial attitude."

We also showed that the estimates of these effects were virtually identical across the two samples of athletes providing strong evidence for the generalizability to the guiding model (Ntoumanis \& Standage, 2009; Vallerand et al., 1997). This evidence becomes stronger if we consider that in the first sample comprised athletes competing in different team sports, such as soccer and rugby that differ with respect to their views of the fair play. For example, rugby has a traditional ethos of sportsmanship and camaraderie to respect opponents and referees and eschew taunting and "trash-talking." In sports where this ethos is less ingrained, such as soccer, such behaviors, as well as other behaviors, such as deliberate fouls, are sometimes used as "tactical" strategies to destabilize and intimidate opponents. These differences were also recently highlighted in a study which showed as the levels of attitudes toward cheating and gamesmanship vary across athletes of different team sports (Ponseti, Cantallops, Borrás, \& García-Mas, 2018).

The present investigation also provided evidence to support the hypothesis that both parents' and coaches' support to athletes' autonomy contribute to the motivational experiences that partly shape athletes' moral attitudes (e.g., see Gagne, Ryan, \& Bargmann, 2003; Smith, Ntoumanis, Duda, \& Vansteenkiste, 2011; Vierling, Standage, \& Treasure, 2007). In addition, we demonstrated that model effects were largely unaffected when controlling for past rule transgressions in sport. Had these effects been nullified by the inclusion of past behavior, it would have rendered the model insufficient as a description of the antecedents of moral attitudes in sport, and of antisocial behavior. These findings are quite relevant given that prior research (e.g., Ajzen, 2002; Conner et al., 1999; Hagger et al., 2016; Hagger et al., 2018; Ouellette \& Wood, 1998; Sutton, 1994) has demonstrated attenuating effects of past behavior on the effects in theories of social cognition and motivation, including models and predictions from self-determination theory (Hagger \& Chatzisarantis, 2009, 2016), in the prediction of prospective behavior in multiple contexts. Current findings suggest that the psychological factors and processes proposed by self-determination theory and theories of antisocial behavior in sport have predictive validity in determining behavior-related transgressive outcomes. As past behavior tends to reflect previous decision-making or unmeasured psychological factors that impact behavior, the current evidence is encouraging given that the past behavior effects are relatively minimal. This means that any factors that predict antisocial behavior beyond past rule transgressions are relevant to explaining the behavior. Of course, this does not mean that the set of factors identified in the current model is definitive, but it does mean that they retain predictive validity and, therefore, could be feasible targets for effective evidence-based interventions to deal with moral transgressions in sport.

Finally, we also demonstrated that athletes' attitudes toward cheating was related to subsequent rule transgressions in sport, as indicated by the number of yellow cards they received in competition. If one considers that athletes' cheating behavior is guided by the goal of "not being caught," the finding of a relation between cheating attitudes and penalties on the field seems particularly relevant. It also is unique, in that existing literature has traditionally focused on self-reported measures of rule-breaking behavior. This notwithstanding, one must also consider that the effects of cheating attitudes on penalties in the current study were relatively small, and that no other attitudinal or motivational factor in the model had effects on this outcome. This may have been a measurement issue due to the generalized nature of the psychological measures used in the current study that may encompass more than officially sanctioned behaviors. There may have been many other morally questionable behaviors which were not seen by the referee or were left unsanctioned because they did not contravene any rule (e.g., sledging), that participants adopted but were not measured in the present investigation.

\subsection{Limitations and suggestions for future research}

It is important to acknowledge the limitations of the current data and the extent to which they can be generalized. As with much of the data in this field, the current data were correlational which is inherently problematic when it comes to inferring causal directions. Although there was a longitudinal component in the current investigation-our measure of transgressive behaviors (referees awarding yellow cards for fouls and rule violations) was collected in the months following the initial psychological measures-this temporal displacement does not mitigate the fact that these data did not model change. Future studies could adopt more powerful longitudinal designs which model change, such as cross-lagged panel designs. This would also enable 
testing of reciprocal effects among the constructs while controlling for intra-individual change.

An additional possible limitation is related to the choice to use the yellow cards received by athletes as an indicator of antisocial behavior, since we have no any information about the exact reason behind each sanction. We acknowledge that although receipt of a yellow card may be an indicator of antisocial behavior, such as a deliberate decision to violate rules to gain an advantage or to act aggressively against the opponent, it may also reflect a technical error. However, in elite and sub-elite athletes, this type of error is less common, and thus our measure may be more likely to reflect antisocial behavior. Other studies (e.g., Vansteenkiste, Mouratidis, \& Lens, 2010) effectively used self-reported sanctions (i.e., yellow cards and penalties) as objective outcomes of moral functioning. In any case, we advocate that future studies should adopt suitable objective measures of other antisocial behaviors such as deliberate fouls, aggressive behaviors, and behaviors against the "spirit" of fair play (e.g., protesting, time wasting, and feigning injury), as well as measures of prosocial behavior that support fair play (e.g., apologizing, accept excuses, and return the ball to opponents after injury stoppage). For example, it would be useful to adapt existing observational instruments developed for use in football playgrounds (e.g., Cruz, Torregrosa, \& Boixadós, 2007) to measure fair play behaviors in match situations.

Another limitation of the present investigation is the lack of any assessment of autonomy support from parents and coaches in the second sample of athletes. This did not allow us to test hypotheses with respect to this aspect of Ntoumanis and Standage's (2009) model alongside the additional measures of moral behavior and past behavior we incorporated in this sample. We look to future research that incorporates all constructs from the original model with our innovations in behavioral measurement. Future studies could also integrate additional constructs from self-determination theory that may strengthen the predictive capacity of the model with respect to athletes' moral attitudes and behaviors. For instance, inclusion of need thwarting (Bartholomew, Ntoumanis, Ryan, \& ThøgersenNtoumani, 2011) and controlling behaviors may be important predictors of athletes' need satisfaction, ill-being, and behavioral problems in sport.

In addition, the current samples of athletes were not selected at random nor were they stratified by age, gender, ethnicity, or demographic background, which limited their generalizability to the wider population of athletes. It must, however, be pointed out that athletes are a very homogenous and select group of individuals, which means that obtaining a "representative" sample of "typical" athletes for a given sport presents considerable challenges. The current data still have value in contributing to the predictors of antisocial behavior in sport and the processes involved as the samples are of reasonable size and reflect more than one sport code. Future research may consider collecting data on larger samples and testing the effects across multiple sport codes, age groups, gender, and other demographic factors likely to impact on these effects. It may be that such data are accumulated over time through multiple research groups and a future quantitative synthesis of the effects proposed in the current model from the multiple tests may provide more definitive data on the generalizability of findings.

An additional consideration is the possibility that the mere fact of asking questions to participants in the current sample may have affected change in the very constructs we aimed to measure. There is research suggesting a "mere-measurement" or "question-behavior" effect in research applying social cognitive and motivational theories to behavior (e.g., Sprott et al., 2006; Wood, Conner, Sandberg, Godin, \& Sheeran, 2014). This has been attributed to raised awareness and accessibility of the constructs involved (Wood et al., 2014). Nevertheless, Spangenberg, Kareklas, Devezer, and Sprott (2016) meta-analysis indicated that the mere-measurement effect is relatively small in size. Nevertheless, as with all research adopting self-report survey measures of social cognitive and motivational constructs, our results should be interpreted in light of this effect.

Finally, it is to highlight that since cheating behavior is generally viewed as socially and culturally undesirable (Lee et al., 2007; Ponseti et al., 2012), self-reports measures of cheating and gamesmanship behaviors may be particularly sensitive to social desirability and impression management biases. Thus, this possible bias may have attenuated the degree of predictability of the model when this measure where included. Future studied need to control the possible effects of social desirability introducing specific measures of this possible bias, and also including objective measures for the past antisocial behaviors.

\subsection{Conclusions and recommendations for practice}

Current findings identify the importance of psychological need satisfaction and motivational constructs from self-determination theory in predicting attitudes toward prosocial and antisocial behaviors, and actual rule transgressions in sport. Results also indicate support for autonomy from parents and coaches as important correlates of need satisfaction in this context. Results indicate pervasive positive effects of need satisfaction and autonomous motivation on keeping winning in perspective, a prosocial moral attitude, and positive effects of controlled motivation on acceptance of gamesmanship and cheating. In addition, attitudes toward both antisocial behaviors linked with rule transgressions indicated by number of yellow cards awarded in competition. Results, in general, held after controlling for past behavior.

Findings of the present research point to some possible practical implications. The findings overall have highlighted the importance of perceived autonomy support and the satisfaction of basic needs. These factors are crucial in fostering athletes' autonomous motivation and, indirectly, in shaping their moral attitudes. In other words, autonomy supportive environments may not only foster one's need satisfaction, volition and autonomous choices and individual volition, but also significantly contribute to promoting positive attitudes toward prosocial behaviors, reducing the risk of acquiring positive attitudes toward antisocial behaviors, and possibly limiting behaviors that are morally questionable. As such, the findings point to the 
importance of significant figures, such as parents and coaches, and to the value of educational approaches seeking to foster environments in which young athletes' autonomy, competence, relatedness, motivation, and moral attitudes are key building blocks of the athletes' growth.

\section{ORCID}

Luca Mallia iD https://orcid.org/0000-0002-8194-8199

\section{REFERENCES}

Ajzen, I. (2002). Residual effects of past on later behavior: Habituation and reasoned action perspectives. Personality and Social Psychology Review, 6, 107-122. https://doi.org/10.1207/ S15327957PSPR0602_02

Bartholomew, K. J., Ntoumanis, N., Ryan, R. M., \& Thøgersen-Ntoumani, C. (2011). Psychological need thwarting in the sport context: Assessing the darker side of athletic experience. Journal of Sport and Exercise Psychology, 33, 75-102. https://doi.org/10.1123/jsep.33.1.75

Boardley, I. D., \& Kavussanu, M. (2007). Development and validation of the moral disengagement in sport scale. Journal of Sport Exercise and Psychology, 29, 608-628. https://doi.org/10.1123/jsep.29.5.608

Boardley, I. D., Kavussanu, M., \& Ring, C. (2008). Athletes' perceptions of coaching effectiveness and athlete-related outcomes in rugby union: An investigation based on the coaching efficacy model. Sport Psychologist, 22, 269-287. https://doi.org/10.1123/tsp.22.3.269

Conner, M., Warren, R., Close, S., \& Sparks, P. (1999). Alcohol consumption and the theory of planned behavior: An examination of the cognitive mediation of past behavior. Journal of Applied Social Psychology, 29, 1676-1704. https://doi.org/10.1111/j.1559-1816.1999.tb02046.x

Cruz, J., Torregrosa, M., \& Boixadós, M. (2007). Behaviours related to fair-play in English and Spanish professional football players. In A. C. Gonçalves, S. Cumming, M. Coelho e Silva, \& R. Malina (Eds.), Sport and education: Tribute to Martin Lee (pp. 155-164). Coimbra, Portugal: Coimbra University (Press).

Cruz, J., Ponseti, F. J., Sampaio, M., Gamito, J. M., Marqués, A., Viñas, J., ... García-Mas, A. (2018). Effect of a psychological training on football grassroot coaches upon young player's fairplay and disposition to cheat. Revista de Psicología del Deporte, 27, 24-30.

d'Arripe-Longueville, F., Corrion, K., Scoffier, S., Rousse, P., \& Chalabaev, A. (2010). Sociocognitive self-regulatory mechanisms governing judgments of the acceptability and likelihood of sport cheating. Journal of Sport and Exercise Psychology, 32(5), 595-618. https://doi. org/10.1123/jsep.32.5.595

Deci, E. L., \& Ryan, R. M. (1985). Intrinsic motivation and self-determination in human behavior. New York, NY: Plenum Press.

Duda, J. L. (1992). Motivation in sport settings: A goal perspective approach. In G. C. Roberts (Ed.), Motivation in sport and exercise (pp. 57-92). Champaign, IL: Human Kinetics.

Esposito Vinzi, V., Chin, W. W., Henseler, J., \& Wang, H. (2010). Handbook of partial least squares: Concepts, methods and applications. Heidelberg, Germany: Springer.

Gagne, M., Ryan, R. M., \& Bargmann, K. (2003). Autonomy support and need satisfaction in the motivation and well-being of gymnasts. Journal of Applied Sport Psychology, 15, 372-390. https://doi. org/10.1080/714044203

Gonçalves, C. E., e Silva, M. J. C., Cruz, J., Torregrosa, M., \& Cumming, S. P. (2010). The effect of achievement goals on moral attitudes in young athletes. Journal of Sport Science and Medicine, 9, 605-611.

Grolnick, W. S., Ryan, R. M., \& Deci, E. L. (1991). The inner resources for school performance: Motivational mediators of children's perceptions of their parents. Journal of Educational Psychology, 83, 508-517. https://doi.org/10.1037/0022-0663.83.4.508

Hagger, M. S., Chan, D. K. C., Protogerou, C., \& Chatzisarantis, N. L. D. (2016). Using meta-analytic path analysis to test theoretical predictions in health behavior: An illustration based on meta-analyses of the theory of planned behavior. Preventive Medicine, 89, 154-161. https://doi.org/10.1016/j.ypmed.2016.05.020

Hagger, M. S., \& Chatzisarantis, N. L. D. (2009). Integrating the theory of planned behaviour and self-determination theory in health behaviour: A meta-analysis. British Journal of Health Psychology, 14(2), 275-302. https://doi.org/ 10.1348/135910708X373959

Hagger, M. S., \& Chatzisarantis, N. L. D. (2015). Self-determination theory. In M. Conner \& P. Norman (Eds.), Predicting and changing health behaviour: Research and practice with social cognition models (3rd ed., pp. 107-141). Maidenhead, UK: Open University Press.

Hagger, M. S., \& Chatzisarantis, N. L. D. (2016). The trans-contextual model of autonomous motivation in education: Conceptual and empirical issues and meta-analysis. Review of Educational Research, 86, 360-407. https://doi.org/10.3102/0034654315585005

Hagger, M. S., Polet, J., \& Lintunen, T. (2018). The reasoned action approach applied to health behavior: Role of past behavior and tests of some key moderators using meta-analytic structural equation modeling. Social Science and Medicine, 213, 85-94. https://doi. org/10.1016/j.socscimed.2018.07.038

Hambleton, R. K. (2001). The nextgeneration of the ITC test translation and adaptation guidelines. European Journal of Psychological Assessment, 17, 164-172. https://doi.org/10.1027//1015-5759.17.3.164

Hodge, K., \& Lonsdale, C. (2011). Prosocial and antisocial behaviour in sport: The influence of motivational climate, autonomous vs controlled motivation, and moral disengagement. Journal of Sport and Exercise Psychology, 33, 527-547. https://doi.org/10.1123/jsep.33.4.527

Kavussanu, M., Seal, A. R., \& Phillips, D. R. (2006). Observed prosocial and antisocial behaviors in male soccer teams: Age differences across adolescence and the role of motivational variables. Journal of Applied Sport Psychology, 18, 326-344. https://doi.org/10.1080/10413 200600944108

Kock, N. (2014). Advanced mediating effects tests, multi-group analyses, and measurement model assessments in PLS-based SEM. Journal International Journal of e-Collaboration, 10, 1-13. https://doi. org/10.4018/ijec.2014010101

Kock, N. (2015). WarpPLS 5.0 user manual. Laredo, TX: Scriptwarp System. Retrieved from http://cits.tamiu.edu/WarpPLS/UserManual_v_5_0. pdf

Lee, M. J., Whitehead, J., \& Ntoumanis, N. (2007). Development of the attitudes to moral decisions in youth sport questionnaire (AMDYSQ). Psychology of Sport and Exercise, 8, 369-372. https://doi. org/10.1016/j.psychsport.2006.12.002

Lee, M. J., Whitehead, J., Ntoumanis, N., \& Hatzigeorgiadis, A. (2008). Relationships among values, achievement orientations, and attitudes in youth sport. Journal of Sport Exercise Psychology, 30, 588-610. https://doi.org/10.1123/jsep.30.5.588

Little, T. D., Cunningham, W. A., Shahar, G., \& Widaman, K. F. (2002). To parcel or not to parcel: Exploring the question, weighing the merits. Structural Equation Modeling, 9, 151-173. https://doi.org/10.1207/ S15328007SEM0902_1

Long, T., Pantaléon, N., Bruant, G., \& D'Arripe-Longueville, F. (2006). A qualitative study of moral reasoning of young elite athletes. Sport Psychologist, 20, 330-334. https://doi.org/10.1123/ tsp.20.3.330

Lucidi, F., Zelli, A., Mallia, L., Nicolais, G., Lazuras, L., \& Hagger, M. (2017). Moral attitudes predict cheating and gamesmanship behaviors among competitive tennis players. Frontiers in Psychology, 8, 571. https://doi.org/10.3389/fpsyg.2017.00571

Mallia, L., Chirico, A., Galli, F., Zelli, A., Sánchez, J. C. J., García-Mas, A., \& Lucidi, F. (2018). The role of achievement goals and moral 
disengagement in explaining moral attitudes and behaviours in sport. Revista de Psicología del Deporte, 27(3), 66-69.

Ng, J. Y. Y., Lonsdale, C., \& Hodge, K. (2011). The basic needs satisfaction in sport scale (BNSSS): Instrument development and initial validity evidence. Psychology of Sport and Exercise, 12, 257-264. https://doi. org/10.1016/j.psychsport.2010.10.006

Ntoumanis, N., \& Standage, M. (2009). Morality in sport: A self-determination theory perspective. Journal of Applied Sport Psychology, 21, 365-380. https://doi.org/10.1080/10413200903036040

Ouellette, J. A., \& Wood, W. (1998). Habit and intention in everyday life: The multiple processes by which past behavior predicts future behavior. Psychological Bulletin, 124, 54-74. https://doi. org/10.1037//0033-2909.124.1.54

Palou, P., Ponseti, F. X., Cruz, J., Vidal, J., Cantallops, J., Borrás, P., \& Garcia-Mas, A. (2013). Acceptance of gamemanship and cheating in young competitive athletes in relation to the perceived motivational climate of parents and coaches. Perceptual and Motor Skills, 117, 1-14. https://doi.org/10.2466/10.30.PMS.117x14z9

Pelletier, L. G., Tuson, K. M., Fortier, M. S., Vallerand, R. J., Briére, N. M., \& Blais, M. R. (1995). Toward a new measure of intrinsic motivation, extrinsic motivation, and amotivation in sports: The sport motivation scale (SMS). Journal of Sport and Exercise Psychology, 17, 35-53. https://doi.org/10.1123/jsep.17.1.35

Ponseti, F. J., Cantallops, J., Borrás, P. A., \& García-Mas, A. (2018). Does cheating and gamesmanship to be reconsidered regarding fair-play in grassroots sports? Revista de Psicologia del Deporte, 27, 28-32.

Ponseti, F. J., Palou, P., Borràs, P. A., Vidal, J., Cantallops, J., Ortega, F., ... Garcia-Mas, A. (2012). Disposition to cheating in sport questionnaire (cded): Its application to young athletes. Revista de Psicologia del Deporte, 21, 75-80.

Reeve, J. (1998). Autonomy support as an interpersonal motivating style: Is it teachable? Contemporary Educational Psychology, 23, 312-330. https://doi.org/10.1006/ceps.1997.0975

Ryan, R. M., \& Deci, E. L. (2000). Self-determination theory and the facilitation of intrinsic motivation, social development, and well-being. American Psychologist, 55, 68-78. https://doi.org/10.1037/0003-066X.55.1.68

Ryan, R. M., \& Deci, E. L. (2017). Self-determination theory: Basic psychological needs in motivation, development and wellness. New York, NY: Guildford Press.

Scanlan, T. K., Carpenter, P. J., Schmidt, G. W., Simons, J. P., \& Keeler, B. (1993). An introduction to the sport commitment model. Journal of Sport and Exercise Psychology, 15, 1-15. https://doi.org/10.1123/ jsep.15.1.1

Sheehy, T., \& Hodge, K. (2015). Motivation and morality in masters athletes: A self-determination theory perspective. International Journal of Sport and Exercise Psychology, 13, 273-285. https://doi.org/10.108 0/1612197X.2014.956326
Smith, A. L., Ntoumanis, N., Duda, J. L., \& Vansteenkiste, M. (2011). Goal striving, coping, and well-being: A prospective investigation of the self-concordance model in sport. Journal of Sport \& Exercise Psychology, 33, 124-145. https://doi.org/10.1123/jsep.33.1.124

Spangenberg, E. R., Kareklas, I., Devezer, B., \& Sprott, D. E. (2016). A meta-analytic synthesis of the question-behavior effect. Journal of Consumer Psychology, 26, 441-458. https://doi.org/10.1016/j. jcps.2015.12.004

Sprott, D. E., Spangenberg, E. R., Block, L. G., Fitzsimons, G. J., Morwitz, V. G., \& Williams, P. (2006). The question-behavior effect: What we know and where we go from here. Social Influence, 1, 128-137. https://doi.org/10.1080/15534510600685409

Sutton, S. (1994). The past predicts the future: Interpreting behaviourbehaviour relationships in social psychological models of health behaviour. In D. R. Rutter \& L. Quine (Eds.), Social psychology and health: European perspectives (pp. 71-88). Aldershot, UK: Avebury.

Tenenhaus, M., Esposito Vinzi, V., Chatelin, Y.-M., \& Lauro, C. (2005). PLS path modeling. Computational Statistics and Data Analysis, 48, 159205. https://doi.org/10.1016/j.csda.2004.03.005

Vallerand, R. J., Briere, N. M., Blanchard, C., \& Provencher, O. (1997). Development and validation of the multidimensional sportpersonship orientations scale. Journal of Sport and Exercise Psychology, 19, 197-206.

Vansteenkiste, M., Mouratidis, A., \& Lens, W. (2010). Detaching reasons from aims: Fair play and well-being in soccer as a function of pursuing performance-approach goals for autonomous or controlling reasons. Journal of Sport \& Exercise Psychology, 32, 217-242. https://doi. org/10.1123/jsep.32.2.217

Vierling, K. K., Standage, M., \& Treasure, D. C. (2007). Predicting attitudes and physical activity in an "at-risk" minority youth sample: A test of self-determination theory. Psychology of Sport and Exercise, 8, 795-817. https://doi.org/10.1016/j.psychsport.2006.12.006

Wood, C., Conner, M., Sandberg, T., Godin, G., \& Sheeran, P. (2014). Why does asking questions change health behaviours? The mediating role of attitude accessibility. Psychology \& Health, 29, 390-404. https:// doi.org/10.1080/08870446.2013.858343

How to cite this article: Mallia L, Lucidi F, Zelli A, Chirico A, Hagger MS. Predicting moral attitudes and antisocial behavior in young team sport athletes: A self-determination theory perspective. J Appl Soc Psychol. 2019;49:249-263. https://doi.org/10.1111/jasp.12581 

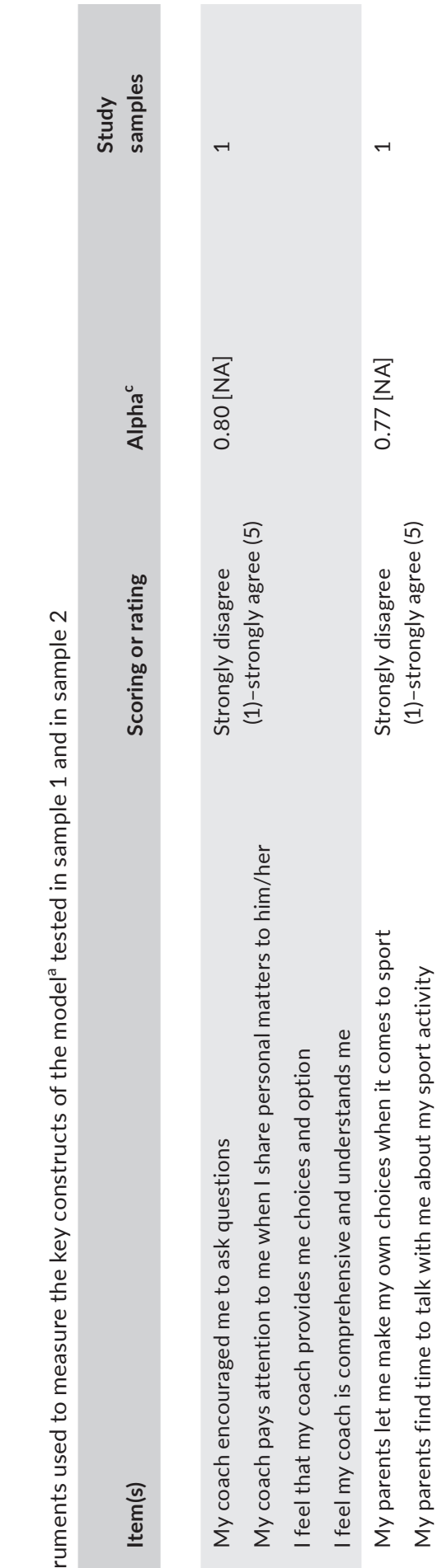<smiles>C1CCCC1</smiles>

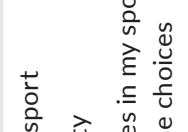
के 过 ठे

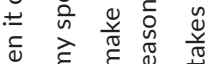

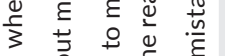

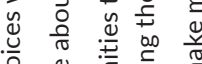
단 产考 ते 은 空 垔 ह

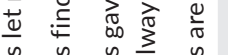
苞茙

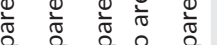

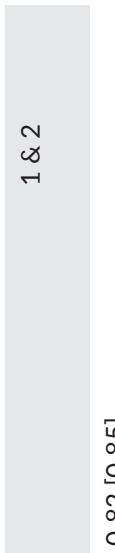

$\sqrt{n}$
$\infty$
0
0
0
0
0
0
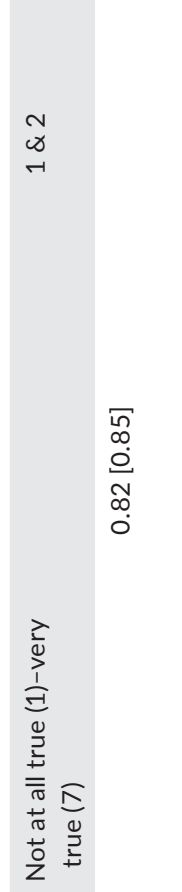

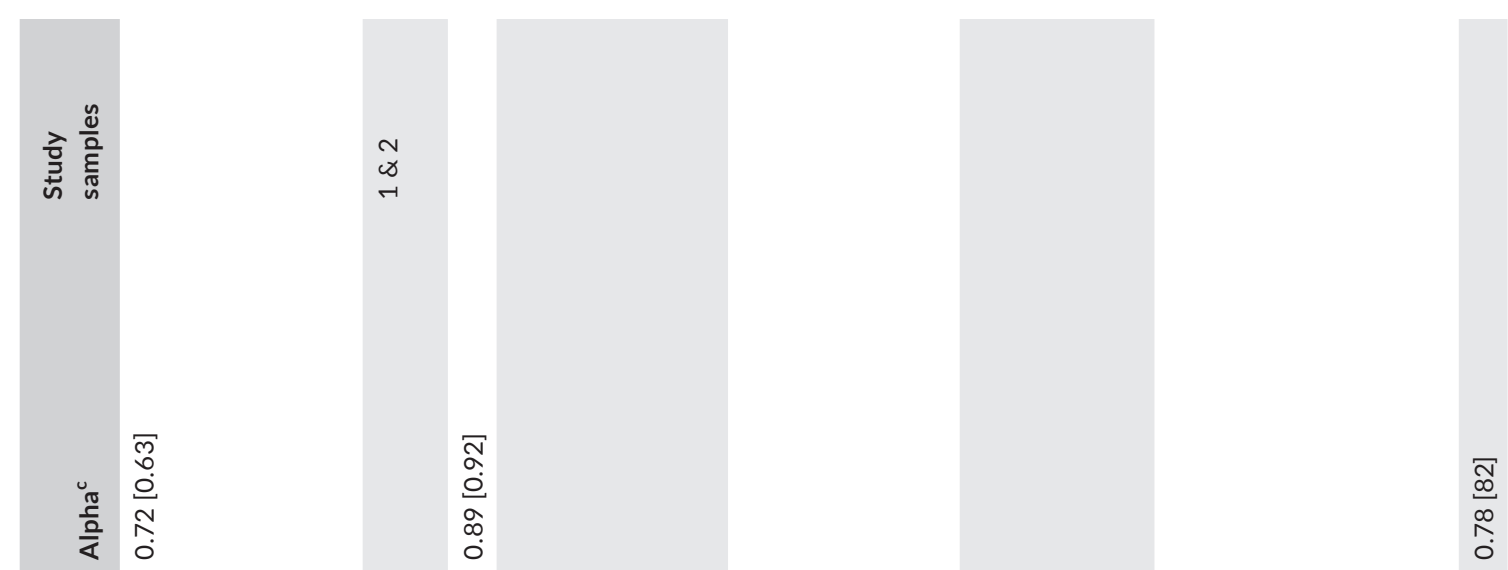

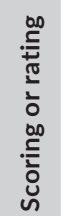
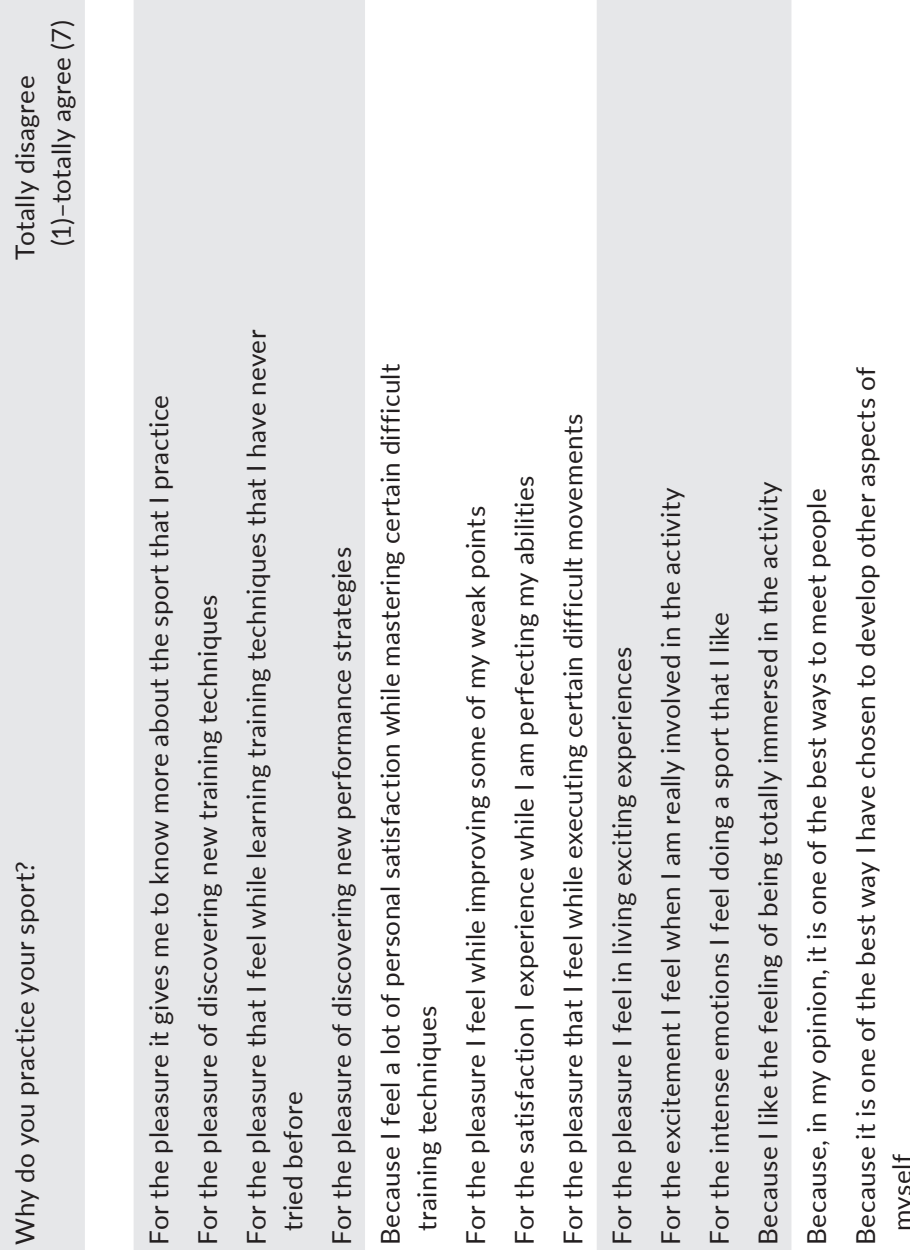

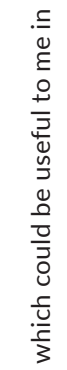

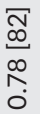
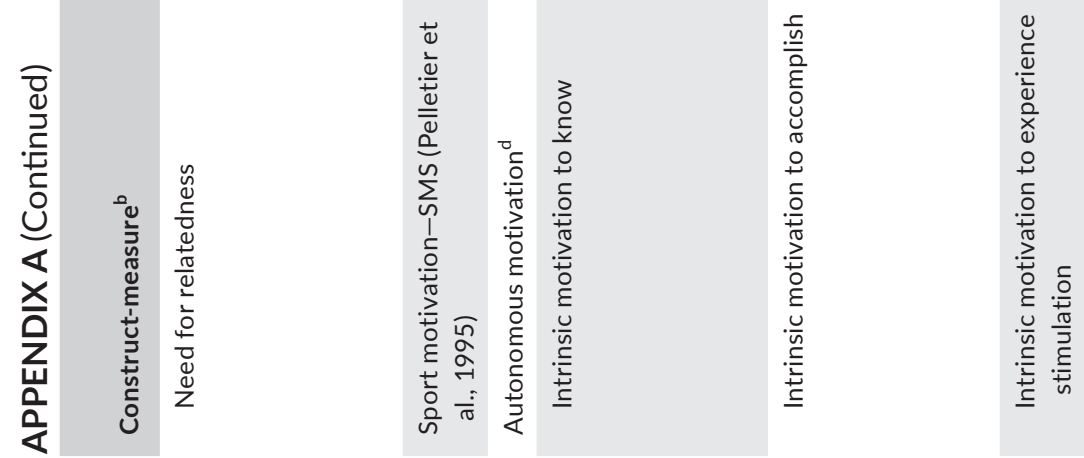

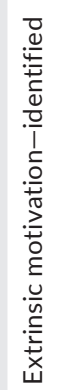

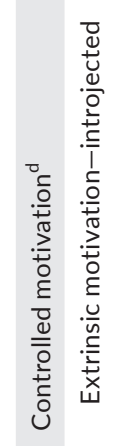




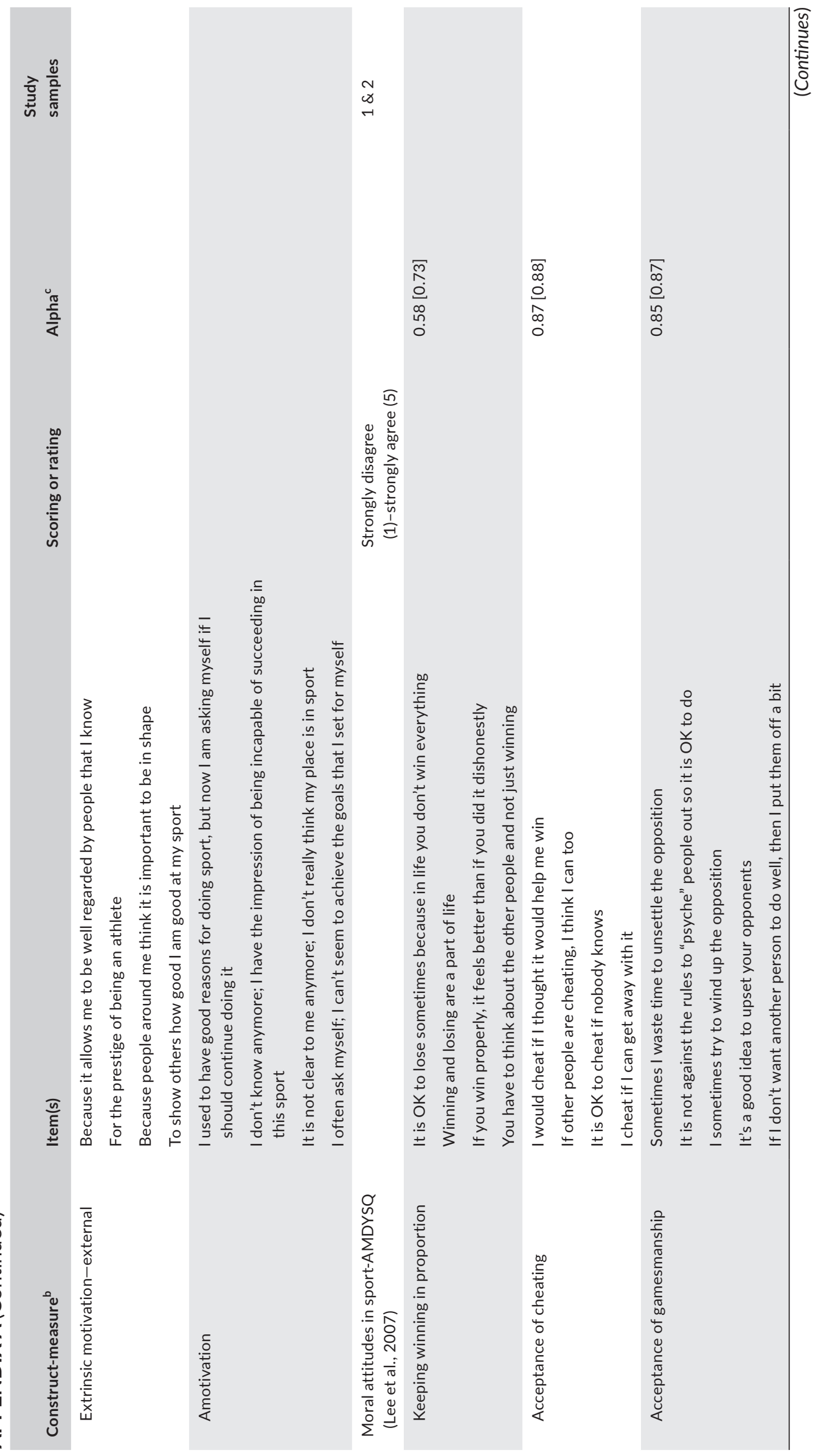




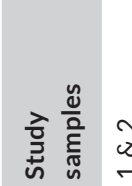

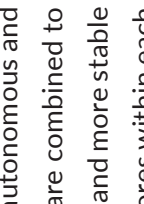

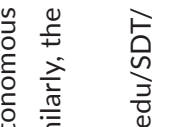

ज苛

N

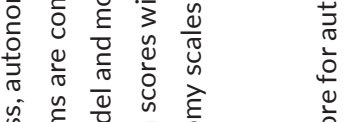

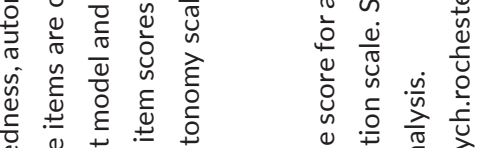
岳

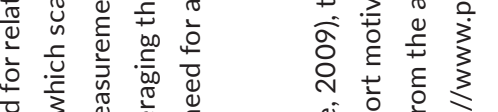

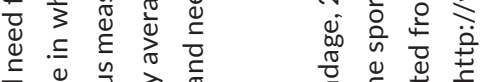

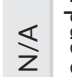

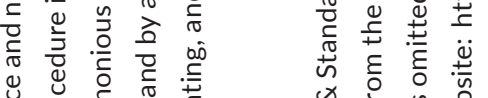

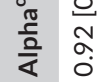

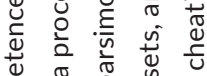

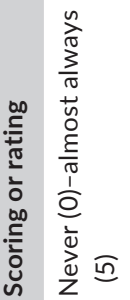
है

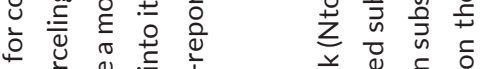

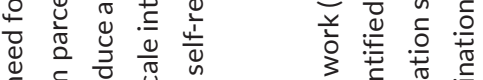

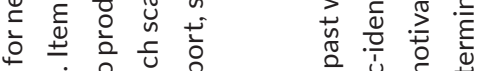

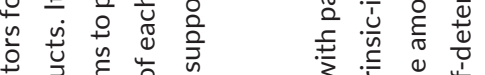

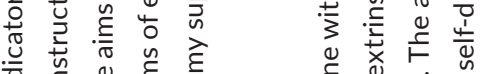
竞

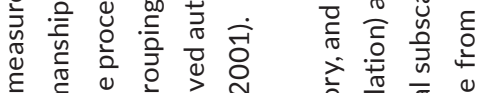
施

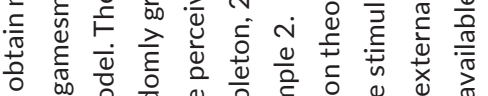
O

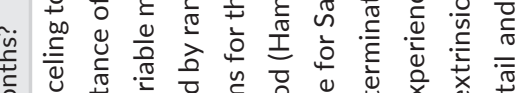

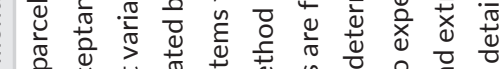

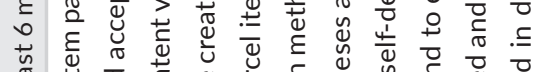
竞

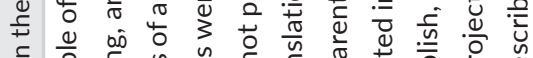

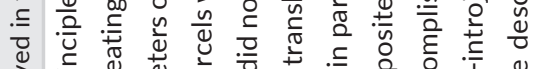

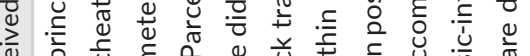

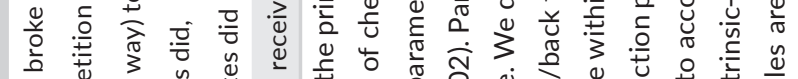

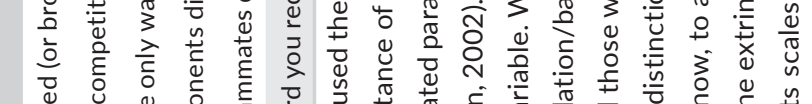

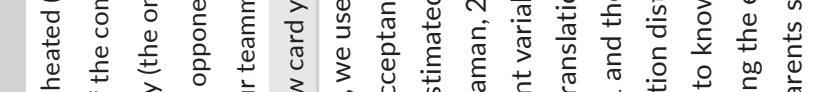

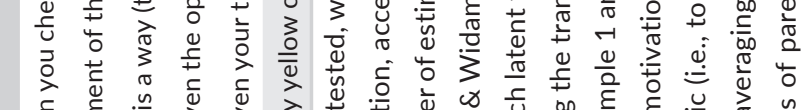
⿹

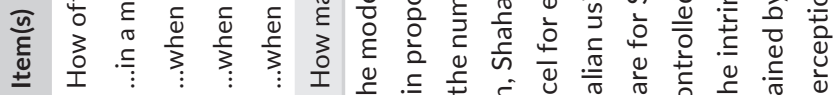

